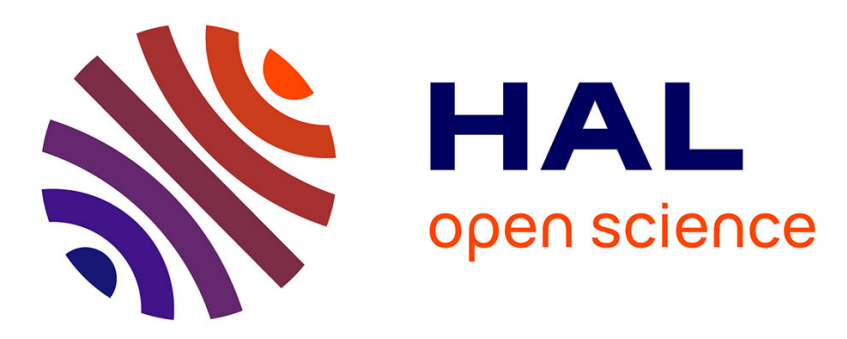

\title{
Seismic evaluation of ordinary RC buildings retrofitted with externally bonded FRPs using a reliability-based approach
}

\author{
Mohammad Ali Mahdavipour, Abolfazl Eslami, Pierre Jehel
}

\section{To cite this version:}

Mohammad Ali Mahdavipour, Abolfazl Eslami, Pierre Jehel. Seismic evaluation of ordinary RC buildings retrofitted with externally bonded FRPs using a reliability-based approach. Composite Structures, 2020, 232, pp.111567. 10.1016/j.compstruct.2019.111567 . hal-03275326

\author{
HAL Id: hal-03275326 \\ https://hal.science/hal-03275326
}

Submitted on 1 Jul 2021

HAL is a multi-disciplinary open access archive for the deposit and dissemination of scientific research documents, whether they are published or not. The documents may come from teaching and research institutions in France or abroad, or from public or private research centers.
L'archive ouverte pluridisciplinaire HAL, est destinée au dépôt et à la diffusion de documents scientifiques de niveau recherche, publiés ou non, émanant des établissements d'enseignement et de recherche français ou étrangers, des laboratoires publics ou privés. 


\title{
Seismic evaluation of ordinary $\mathrm{RC}$ buildings retrofitted with externally bonded FRPs using a reliability-based approach
}

\author{
Mohammad Ali Mahdavipour ${ }^{1}$, Abolfazl Eslami² $^{*}$ Pierre Jehel $^{3}$ \\ ${ }^{1} \mathrm{PhD}$ Research Fellow, Department of Engineering Sciences, University of Agder, Norway. \\ (Email: ali.mahdavipour@uia.no) \\ ${ }^{2}$ Assistant Prof., Department of Civil Engineering, Yazd University, Iran. \\ (Email: a.eslami@yazd.ac.ir) \\ ${ }^{3}$ Assistant Prof., Laboratory MSSMat-UMR CNRS 8579, Université Paris-Saclay, CentraleSupélec, France. \\ (Email: pierre.jehel@,centralesupelec.fr)
}

\footnotetext{
*Corresponding author: Abolfazl Eslami

Assistant Professor, Department of Civil Engineering

Yazd University, Yazd, Iran

Email: a.eslami@yazd.ac.ir

Phone: +989133554249
} 


\begin{abstract}
Despite the extensive literature on reinforced concrete (RC) members retrofitted with fiberreinforced polymer (FRP) composites, few studies have employed a reliability-based approach to evaluate the seismic performance of RC buildings in terms of their collapse capacity and ductility. In this study, the performance of a poorly-confined RC building structure is investigated for different FRP retrofitting schemes using different configurations and combinations of wrapping and flange-bonded FRPs, as two well-established techniques. A nonlinear pushover analysis is then implemented with a computational reliability analysis based on Latin Hypercube Sampling (LHS) to determine the collapse capacity and ductility of the case-study structure. The variations in material properties and applied loads are examined using a rational probabilistic procedure. The results demonstrate the effectiveness of the reliability approach as it is capable of providing reliable and accurate comparisons between the retrofitting schemes implemented. In addition, the failure modes of the original and retrofitted frames are scrutinized for a more detailed study. It was found that the failure mode of the casestudy building is remarkably dependent on the variations of both the input parameters and the adopted retrofitting scheme.
\end{abstract}

\title{
KEYWORDS
}

Reliability; FRP; Retrofitting; RC buildings; Failure mode; Collapse capacity; Ductility

\section{Introduction}

The advantageous properties of externally bonded fiber-reinforced polymer (FRP) composites such as high tensile strength, corrosion resistance, and ease of installation have nominated them as a distinct option for seismic retrofitting of reinforced concrete (RC) structures. Over the past two decades, FRP composites have received wide acceptance worldwide and many research endeavors have conducted to explore the different aspects of their application and to address the associated challenges. The results of these studies have been beneficially employed in developing design codes and guidelines for real field applications.

In general, FRP composites can be implemented to enhance both the loading capacity and ductility of RC structures using different retrofitting schemes. Flexural retrofitting is a widely used approach that would serve not only to increase the loading capacity of members and structures but also under certain circumstances, to relocate plastic hinges in beams away from the column interface as well [1-3]. The latter capability can change the failure mode from a 
column-sway to a beam-sway one. A viable scheme to enhance flexural capacity is the flangebonded FRPs in which FRP composites can be applied to critical regions of both beams and columns without any extreme damage to the slab. However, debonding is still a major issue of concern that can decrease the efficiency of such externally bonded FRP flexural retrofits. As a remedy, newly proposed anchorage systems are reliable solutions to overcome this undesirable failure mode [1, 4-6].

In an experimental investigation, Eslami and Ronagh [1] investigated the retrofitting of damaged/undamaged RC Beam-Column sub-assemblages using the flange-bonded FRP composites. Their results showed that the proposed technique when combined with a grooving anchorage system was effective in both increasing the flexural capacity and relocating plastic hinges away from the column interface. Compared to the pre-cracked control specimen, the retrofitted joints led to an increase of $30 \%$ in ultimate capacity. As expected, however, the displacement ductility factor of the retrofitted joint reportedly decreased due to the increased reinforcement ratio provided by the externally bonded FRPs.

Flange-bonded FRPs have also been used to improve the lateral behavior of an 8-story RC building by Ronagh and Eslami [7]. Comparison of the capacity curves obtained from nonlinear pushover analysis confirmed increments of $43 \%$ and $80 \%$ in the capacity of the selected building as a result of using glass FRP (GFRP) and carbon FRP (CFRP) composites, respectively. Although CFRP was observed to outperform GFRP in terms of lateral capacity, the former was associated with a lower ductility. Eslami et al. [8] used the nonlinear timehistory analysis to find that CFRP flange-bonded retrofits were able to reduce the maximum inter-story drift of the same 8 -story building under near-fault ground motions from $3.3 \%$ in the as-built to $2.4 \%$ in the retrofitted building.

On a par with flexural retrofitting scenario, FRP wraps can be effectively used for additional confinement in regions prone to plastic deformations. Towards this, Di Ludovico et al. [9] investigated the seismic performance of a 3-story RC building retrofitted with a combination of wrapped and web-bonded glass FRPs (GFRPs). The results obtained from their pseudodynamic loading showed that the retrofitted building was able to resist by around $50 \%$ higher peak ground accelerations (PGA). Further, the findings demonstrated the efficiency of FRP composites in improving the global performance of the building in terms of both ductility and energy dissipation capacity. Similar conclusions have been also reported elsewhere [10-12]. 
The studies cited above used deterministic procedures to investigate the performance of FRP retrofitted RC structures neglecting the fact that these structures might behave differently due to unpredicted uncertainties in loads, material properties, and geometry. In reaction to this shortcoming, some studies used reliability-based approaches in the element scale to study the performance of RC members such as beams [13-16] and columns [17-19] retrofitted with externally bonded FRP composites. However, few studies were focusing on implementation of such reliability-based approaches to upgrade the performance of RC structures at the macro level.

To achieve a predefined performance in RC structures, Zou et al. [20] proposed a reliabilitybased algorithm to optimize the amount of FRP confinement in a building. Focusing solely on earthquake uncertainties, their study ignored structural uncertainties such as those associated with material properties in order to reduce the size of the optimization problem to a reasonable level. Using a reliability-based approach, Ali et al. [21] compared the effects of FRP confinement (in columns) with those of a combined flexural (in beams and columns) and confining (in columns) FRPs in a 3-story RC building. For these two retrofitting options, fragility curves were compared based on the maximum lateral drift of the top story. The results confirmed a notable increase (32\%) in the reliability of the RC building treated with both flexural and confining FRPs, while sole application of the FRP wraps was only able to improve the reliability of the building by approximately $16 \%$. Although their study demonstrated the effectiveness and significance of reliability assessment, little attention was paid to the collapse capacity of the building. A probabilistic procedure seems necessary when seeking an accurate judgment of the collapse capacity of the structure and a rationale comparison of the different retrofitting solutions.

The above considerations were the main motivation beyond the current study aimed at investigating the seismic behavior of ordinary RC buildings retrofitted with externally bonded FRP composites. To achieve this objective, the flexural and confining FRP composites, as the most prevalent techniques in FRP applications, were used in different configurations and combinations. As a case-study building, a 4-story ordinary RC building was considered and the results were examined in terms of collapse capacity, displacement ductility, and failure mode. 


\section{Methodology}

The seismic performance of structures retrofitted with externally bonded FRP composites may be affected by uncertainties from a variety of sources that can be classified into the categories of materials, loads, and geometry [22]. Accurate assessment of the seismic performance of such structures requires the effects of variations in each of the input variables to be taken into account in order to obtain the distribution of structural responses. Using an appropriate sampling method, inputs may be randomly generated for structural analysis and the distribution of responses can be determined. In other words, in a reliability-based assessment, both structural inputs and outputs have probability distributions rather than deterministic values. This approach seems useful not only for the assessment of the behaviors of different retrofitting schemes but also for their accurate and reliable comparisons, especially in the decision-making step. Fig. 1 shows a general overview of the steps of the proposed reliability-based approach.

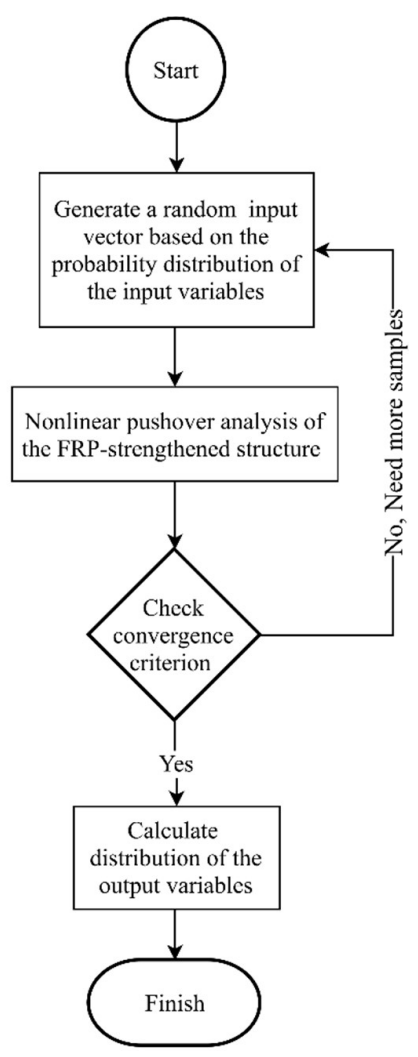

Fig. 1. Steps of the reliability-based seismic assessment of RC structures using a sampling method and a nonlinear pushover analysis.

The first step involves defining random input parameters and determining their variations. In practice, a broad number of random input parameters are known to affect the responses of an 
RC structure. However, including all the sources of uncertainty in a model might increase the problem size and its computational time and cost. On the other hand, given the maximum construction tolerances required by design codes [23], some sources of uncertainty, like geometry, are of less importance at the structural level [21]. Hence, the effects of geometrical parameters were ignored in this study. Table 1 lists the random input variables and their probability distributions involved in the reliability-based assessment of FRP-retrofitted structures in the current study. The references from which the parameters of probability distributions were adopted are also listed in the last column of Table 1.

Concerning the uncertainties associated with seismic loading, either of the two approaches of incremental dynamic analysis (IDA) [24] or nonlinear pushover analysis may be implemented. While the use of a set of ground motions presenting different intensity levels (IDA) is the most reliable option to assess the structural responses [25], repetition of that for each generated random sample would dramatically increase the total number of the analysis. Such analyses would be tedious and time-consuming given the iterative nature of reliability-based studies. Despite that IDA might be possible for low-rise buildings and for research purpose, this study focused on nonlinear pushover analysis to be more applicable to the real projects through which a broad and effective perspective can be provided for design engineers.

In addition, there is a potentially significant amount of uncertainty that comes from the damping modeling in nonlinear time history analysis [26]. These limitations encouraged the use of nonlinear pushover analysis as an alternative.

For lateral loading pattern, the first mode shape of the structure was obtained based on random input vectors as follows:

Random input vector $=\left[F_{c} F_{y} E_{s} F_{f u} E_{f} D L L L Y_{m}\right]$

The definitions for the random input variables in relation (1) are provided in Table 1. 
Table 1. Probability distributions of the random input variables used.

\begin{tabular}{|c|c|c|c|c|c|c|}
\hline Variable & Unit & Distribution & Mean & $\mathrm{SD}^{*}$ & $\mathrm{CV}^{\#}$ & Reference \\
\hline $\begin{array}{c}\text { Compressive strength of } \\
\text { concrete }\left(f^{\prime} c\right)\end{array}$ & $\mathrm{MPa}$ & Log-normal & 25 & 4 & 0.16 & {$[14,18,21,27,28]$} \\
\hline $\begin{array}{l}\text { Yield strength of steel rebar } \\
\left(f_{y}\right)\end{array}$ & $M P a$ & Log-normal & 420 & 42 & 0.1 & {$[18]$} \\
\hline $\begin{array}{l}\text { Elastic modulus of steel rebar } \\
\left(E_{s}\right)\end{array}$ & $M P a$ & Normal & 200000 & 6600 & $\begin{array}{c}0.03 \\
3 \\
\end{array}$ & {$[18,21,29]$} \\
\hline $\begin{array}{l}\text { Ultimate tensile strength of } \\
\qquad F R P\left(f_{f u}\right) \\
\end{array}$ & $M P a$ & Weibull & 620.5 & 93 & 0.15 & {$[18,21,28,30]$} \\
\hline $\begin{array}{c}\text { Tensile elastic modulus of FRP } \\
\left(E_{f}\right)\end{array}$ & $M P a$ & Log-normal & 51700 & $\begin{array}{c}1034 \\
0 \\
\end{array}$ & 0.2 & {$[28,30]$} \\
\hline Dead load $(D L)$ & $k N$ & Normal & $1.05 D L$ & 0.105 & 0.1 & {$[18,31]$} \\
\hline Live load ( $L L)$ & $k N$ & $\begin{array}{c}\text { Extreme type } \\
I\end{array}$ & $1 L L$ & 0.25 & 0.25 & {$[18,21,31]$} \\
\hline Model error $\left(\Upsilon_{m}\right)$ & - & Normal & 1 & 0.05 & 0.05 & {$[21,27]$} \\
\hline
\end{tabular}

${ }^{*}$ SD: Standard deviation

${ }^{\#} \mathrm{CV}$ : Coefficient of variation

The Latin Hypercube Sampling (LHS) method was implemented to generate random input vectors from the predefined probability distributions of input variables. Compared to the crude Monte Carlo sampling method, LHS is a stratified one that provides more accurate evaluations of the problem distribution with a smaller number of samples [32]. In this method, the probability distribution of each random variable is divided into non-overlapping intervals of equal probability before selecting one random value in each interval [32]. This avoids taking all the samples from the same region of probability distribution, thereby optimizing the convergence time and improving the computational efficiency. Since the input of the structural model is a vector, the values selected for different variables should be paired randomly in a matrix called the 'random input matrix' [32]. For instance, the random input vector selected in this study contained eight elements, as observed in relation (1), while the probability distributions were divided into ten intervals (with equal probabilities of $10 \%$ ). As a result, the random input matrix for one iteration of the LHS would be a $10 \times 8$ matrix.

When a sample was generated and the structural model analyzed, the deviation in the average of output results was used to estimate the final number of samples as a convergence criterion of LHS. Based on Bayesian probability, the number of samples $(\mathrm{N})$ needed for a deviation of less than $l$ in the average number of outputs $(\mu)$ can be estimated by [33]:

$$
N=\frac{4 z_{\alpha}^{2}}{l^{2}} \times s_{0}^{2}-k_{0}
$$


in which, $s_{0}^{2}$ and $k_{0}$ are the variance and number of samples generated in advance. Also, $z_{\alpha}$ is the normal probability of $(1-2 \alpha) 100 \%$ credible interval. In this study, $1 \%$ of the average value of the results was considered as an acceptable convergence tolerance with a $95 \%$ credible interval $(\alpha=0.025)$. In other words, if the calculated value for $(N)$ becomes zero, with a 95\% credible interval, generating a new sample deviates the average of the outputs less than $1 \%$.

\section{Description of the original building}

The structure considered in this study was an ordinary moment-resisting $\mathrm{RC}$ frame as part of a lateral resisting system of a four-story residential building with three equal bays of $5 \mathrm{~m}$. Each story was taken to be $3 \mathrm{~m}$ in height. The structural design of the frames was based on the ordinary provisions of ACI 318-14[34]. In addition, the base shear seismic design was determined considering a peak ground acceleration of $0.3 \mathrm{~g}$ that is related to a high seismic zone based on the Iranian seismic design code [35], which is similar to the Uniform Building Code (1997) [36]. In the design of this moment-resisting frame, the design dead and live loads were assumed to be equal to $40 \mathrm{kN} / \mathrm{m}$ and $10 \mathrm{kN} / \mathrm{m}$, respectively. In addition to these gravity loads, the self-weight of the building was also included in the design load. The compressive strength of concrete was taken equal to $25 \mathrm{MPa}$ and Grade $60\left(\mathrm{f}_{\mathrm{y}}=420 \mathrm{MPa}\right)$ ribbed bars were used as internal reinforcement. Moreover, a clear concrete cover of $45 \mathrm{~mm}$ was assumed for all the beams and columns. In order to simulate poorly-confined conditions, the shear design of the frame was based on the shear forces induced in the beams and columns but ignoring the special seismic detailing. Consequently, stirrups of $8 \mathrm{~mm}$ in diameter were deployed at intervals of $170 \mathrm{~mm}$ along all the beams and columns. In terms of dynamic characteristics, the first mode of vibration possesses a period $\left(T_{1}\right)$, modal mass coefficient $\left(\alpha_{1}\right)$, and modal participation factor $\left(\mathrm{PF}_{1}\right)$ of $0.781 \mathrm{~s}, 0.771$, and 1.309 , respectively. Fig. 2 shows the details of the geometry and reinforcement of the designed frame. 


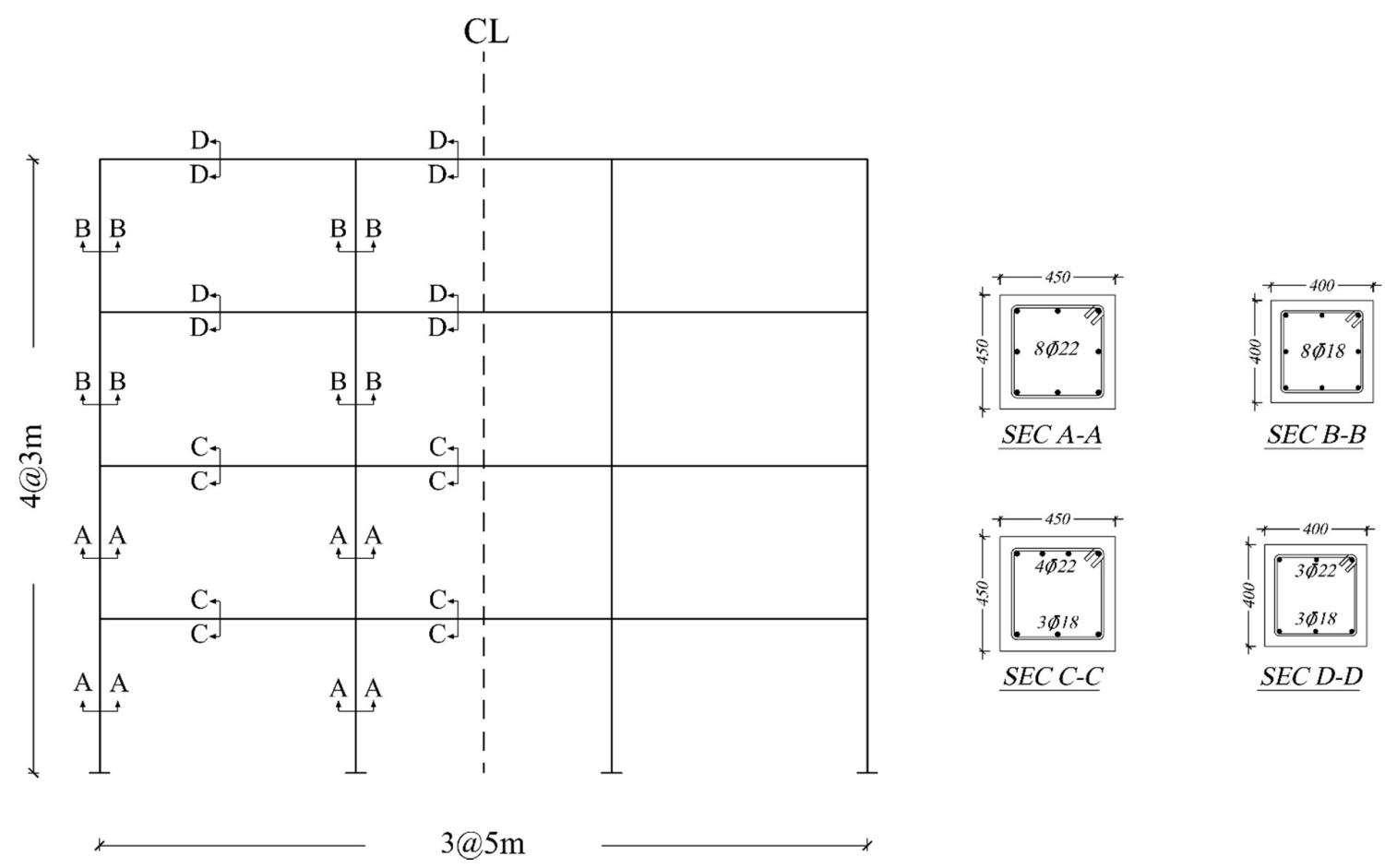

Fig. 2. Geometric and reinforcement details of the original frame

\section{Retrofitting schemes}

The retrofitting strategies adopted were assumed to enhance the flexural and/or ductility behavior(s) of the structure. Towards this, different schemes of CFRP composites were applied to the regions prone to plastic deformations near the beam-column connections in the casestudy frame as schematically shown in Fig. 3. In order to assess the influences of flexural and confining retrofits separately, all the CFRP layers were assumed to be unidirectional.

The first scheme contained the application of the flange-bonded FRP retrofits to increase the flexural capacities of beams and columns, as illustrated in Fig. (3a). The length of the flexural retrofits was assumed to be twice the depth of the section (2h). This value is approximately twice and equal to the plastic hinge length for columns and beams, respectively, as recommended in ACI 440.2R-17 [37]. The second scheme was intended to improve the ductility of columns through the application of CFRP wraps in their plastic hinge regions as shown in Fig. 3(b). The wrapping length was also selected to be twice the depth of the columns. It should be noted that the connected slab in a real application would impede complete wrapping of beams. Thus, complete wrapping was only applied to the columns. The third scheme was a combination of the other two schemes, in which the flange-bonded CFRP 
composites were installed in both the beams and column while columns were additionally wrapped with confining FRP layers as shown in Fig. (3c). In order to evaluate the effect of reinforcing ratio, the number of retrofitting layers was assumed to vary between 3 and 6 , each $0.7 \mathrm{~mm}$ in thickness $\left(t_{f}=0.7 \mathrm{~mm}\right)$. Table 2 reports the test matrix together with the details of different retrofitting schemes adopted in this study.

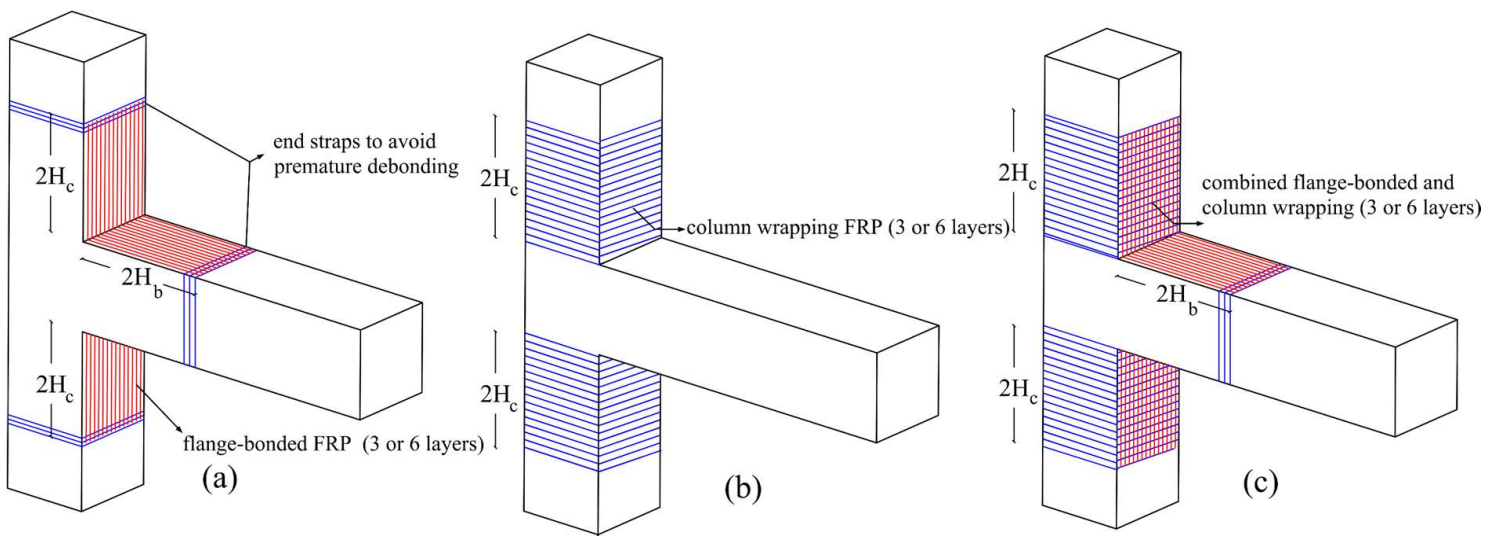

Fig. 3. Three different retrofitting schemes: a) flange-bonded FRP with end straps, b) column wrapping, c) combined flange-bonded and column wrapping 
Table 2. Test matrix and retrofitting schemes

\begin{tabular}{ccccc} 
& \multicolumn{2}{c}{ Beams } & \multicolumn{2}{c}{ Columns } \\
\cline { 2 - 5 } Notation & $\begin{array}{c}\text { Flexural } \\
\text { Layers }\end{array}$ & $\begin{array}{c}\text { Confining } \\
\text { Layers }\end{array}$ & $\begin{array}{c}\text { Flexural } \\
\text { Layers }\end{array}$ & $\begin{array}{c}\text { Confining } \\
\text { Layers }\end{array}$ \\
\hline Original & - & N/A & - & - \\
\hline 3-Flexural & 3 & N/A & 3 & - \\
\hline 6-Flexural & 6 & N/A & 6 & - \\
\hline 3-Confined & - & N/A & - & 3 \\
\hline 6-Confined & - & N/A & - & 6 \\
\hline 3-Combined & 3 & N/A & 3 & 3 \\
\hline 6-Combined & 6 & N/A & 6 & 6 \\
\hline N/A: Notapplicable & & & &
\end{tabular}

N/A: Not applicable

\section{Nonlinear model}

The nonlinear modeling and pushover analysis of the original and retrofitted frames were carried out in the OpenSees environment [38]. Since the fiber section can consider the P-M interaction inherently, both the beams and columns were modeled using the DisplacementBased Beam-Column element with fiber formulation [38, 39]. It is also possible to model the progressive failure of a section by removing fibers that meet material failure. All the structural members were divided into three parts: two end segments with a length equal to $2 \mathrm{~h}$ (along which FRP laminates were applied in the retrofitted frames) and a middle segment identically modeled in both the original and retrofitted frames. Each of these three parts modeled by 5 integration points (control sections) as illustrated in Fig. 4 to monitor the behavior of the frame elements while elastic elements were used to simulate the behavior of the joint panel zone. It is worth noting that the same approach has been also used by others [39]. 


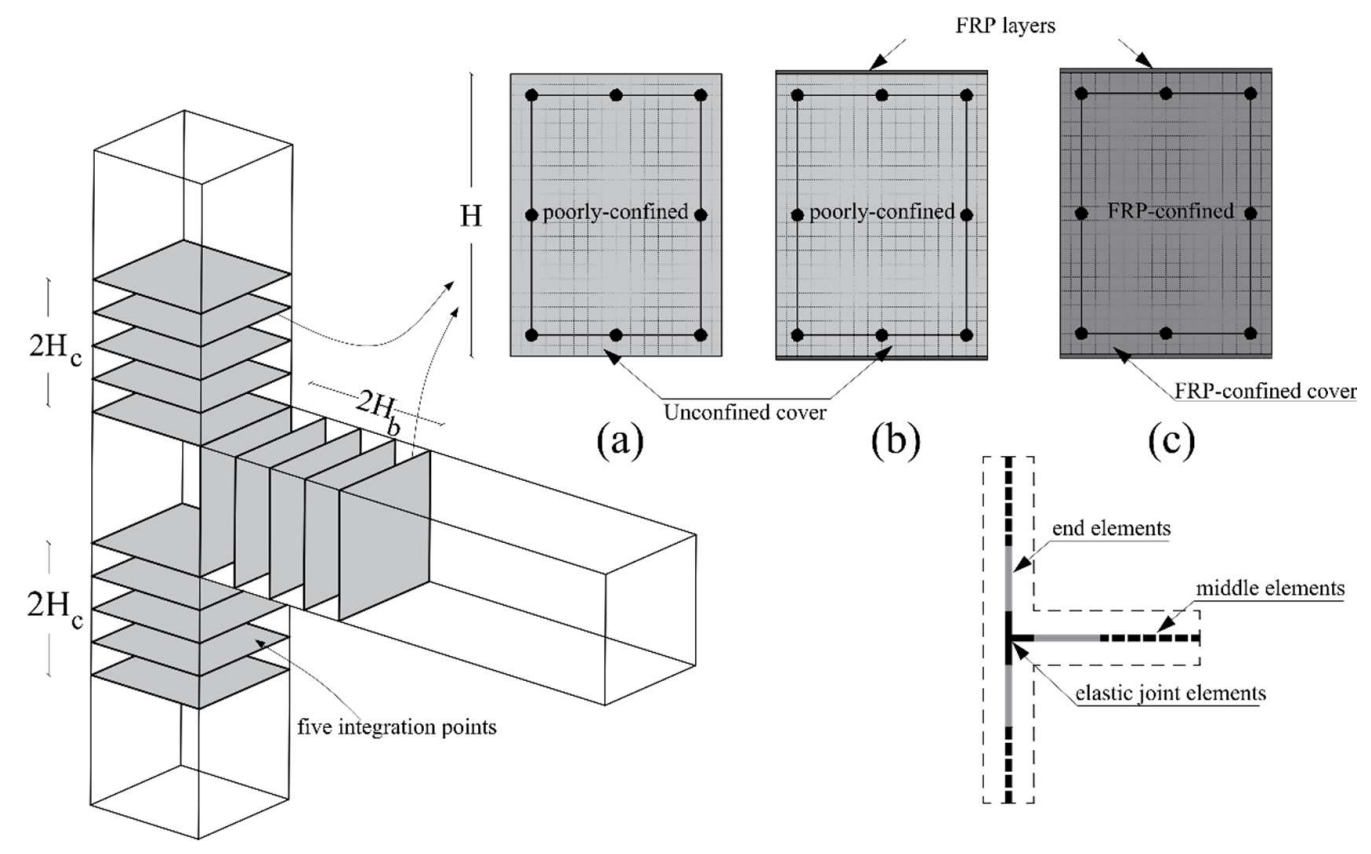

Fig. 4. Configuration of the numerical model and fiber sections for a) non-retrofitted sections b) flange-bonded FRP sections c) combined flange-bonded and column wrapped sections.

Several constitutive models can be found in the literature to predict the nonlinear stress-strain behavior of FRP confined concrete. Herein, the model proposed by Lam and Teng [40, 41] was used as it has been claimed to provide the most accurate prediction of the ultimate strength and strain in FRP-confined circular and rectangular columns [42, 43]. It is worth noting that this model has been also adopted by ACI 440.2-17[37]. Further, the unconfined concrete was modeled using a bilinear representation constituting an elastic behavior followed by a horizontal straight line.

Fig. (5a) shows the constitutive models considered for the confined and unconfined concrete materials where, $f_{c}^{\prime}$ and $E_{c}$ are the compressive strength and elastic modulus of concrete, respectively. For normal-weight concrete, $E_{c}$ can be calculated as [34]:

$$
E_{c}=4700 \sqrt{f_{c}^{\prime}}(\text { in } M P a)
$$

In addition, $\varepsilon_{c}^{\prime}$ is the compressive strain corresponding to $f_{c}^{\prime}$ taken to be equal to 0.002 as recommended in ACI 440.2R-17 [37] and elsewhere [44-46]. The maximum compressive strength of confined concrete $\left(f_{c c}^{\prime}\right)$ and its ultimate compressive strain $\left(\varepsilon_{c c u}\right)$ were calculated based on the maximum confining pressure $f_{l}$, a strain efficiency factor of $k_{\varepsilon}=0.57$, and shape factors of $K_{a}$ and $K_{b}$ as described in Lam and Teng [40, 41] . Furthermore, a threshold of 0.01 
was considered for the maximum compressive strain of FRP-confined concrete as higher values would lead to a loss of concrete integrity [37]. The slope of the second portion of the stressstrain model for FRP-confined concrete $\left(E_{2}\right)$ can be obtained as follows [37]:

$$
E_{2}=\frac{f_{c c}^{\prime}-f_{c}^{\prime}}{\varepsilon_{c c u}}
$$

This hardening branch in confined concrete is solely valid if the ratio $f_{l} / f_{c}^{\prime}$ is larger than 0.08 [37, 40, 41]. This minimum level of confinement was controlled for all the sections with providing a minimum number of confining layers $\left(\mathrm{n}=3, t_{f}=0.7 \mathrm{~mm}\right)$.

The tensile strength of the concrete material was ignored in the nonlinear model as stress in all concrete fibers at failure is expected to exceed concrete rupture strength to a great extent.

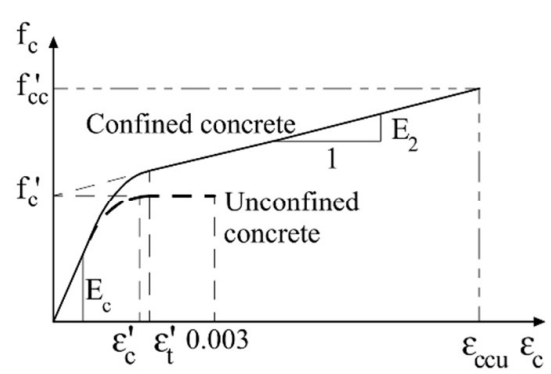

(a)

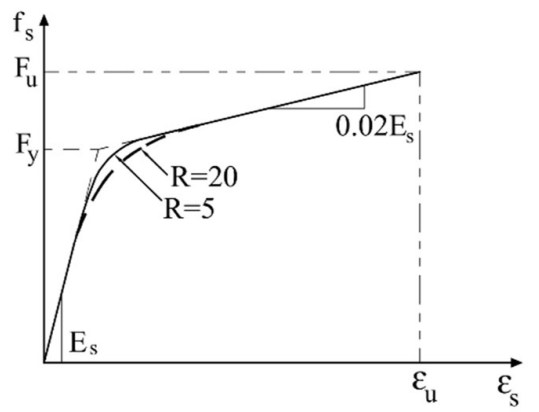

(b)

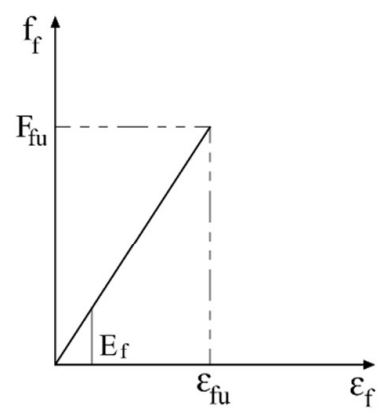

(c)

Fig. 5. Constitutive models for a) FRP-confined and unconfined concrete, b) Giuffré-Menegotto-Pinto material (Steel 02) for steel rebars, and c) FRP composites.

As shown in Fig. 5(b), the behavior of the steel reinforcement in the fiber section was simulated using the Giuffré-Menegotto-Pinto material (Steel 02) with a 2\% strain hardening ratio as proposed elsewhere $[38,47]$. In addition, Fig. 5(c) illustrates the behavior of the flange-bonded FRP sheets modeled by an elastic no-compression material.

For each iteration of the reliability analysis, the material parameters of the described models were randomly generated based on their distributions reported in Table 1. It should be noted that some other parameters are a function of these random variables. For example, as Eq. (3) shows, the elastic modulus of concrete depends on its compressive strength. In consequence, a random change in the compressive strength of concrete leads to a variation of the elastic modulus.

All the materials were also integrated with MinMax material to remove fibers when reaching their fracture strain. In fact, the MinMax material in OpeeSees defines the minimal and 
maximal bounds of strain of the other predefined materials [38]. In case the strain of a fiber exceeds such bound thresholds, the main material of that fiber stops working [48]. Table 3 lists the maximal and minimal strain bounds implemented for each material in the current study. All the seismic lumped masses (for modal analysis) and gravity loads were obtained based on all the dead load including the self-weight of the frame plus $20 \%$ of the live load [35].

Table 3. Minimum and maximum strain bounds considered for material failure.

\begin{tabular}{lcc} 
Material & $\begin{array}{c}\text { Minimum strain } \\
\text { (compression) }\end{array}$ & $\begin{array}{c}\text { Maximum strain } \\
\text { (tension) }\end{array}$ \\
\hline Unconfined concrete & 0.003 & $\infty$ \\
\hline Confined concrete & Min $\left(0.01, \varepsilon_{c c u}\right)$ & $\infty$ \\
\hline Steel rebar & 0.1 & 0.1 \\
\hline FRP laminates & $\infty$ & $\varepsilon_{f u}=f_{f u} / E_{f}$ \\
\hline
\end{tabular}

Note: $\infty$ means that the material can be deformed extensively without failure.

\section{Capacity and ductility assessments}

In seismic evaluation of structures, ductility is defined as their ability to sustain large post-yield deformations without a considerable loss in their lateral resistance. As different parts of a structure would not yield concurrently, there is no obvious yield point in nonlinear loaddisplacement curves of a structure subjected to lateral loading. Consequently, locating a yield point to determine the ductility factor for the overall behavior of the structure is somehow subjective. A widely accepted approach is to use an idealized bilinear curve. Herein, the procedure proposed in FEMA P695 [49] was adopted to obtain the idealized bilinear curve of the real pushover curves and to determine the ductility factor. As shown in Fig. (6), the elastic stiffness and ultimate strength of both curves are identical while the inelastic portion of the bilinear curve is horizontal. To determine ultimate roof displacement $\left(\delta_{u}\right)$, two criteria were considered in this study for determining the collapse point in the pushover curves. The first criterion, as recommended by FEMA 356 [50], requires a maximum inter-story drift of 4\% [50] whereas the second one, as stipulated in FEMA P695 [49], requires a 20\% loss in the ultimate shear capacity of the real pushover curve. In each step of the analyses, these two criteria were 
controlled to find the ultimate roof displacement. Then, the ductility factor can be defined as [49]:

$$
\mu_{t}=\frac{\delta_{u}}{\delta_{y, e f f}}
$$

where, $\delta_{y, \text { eff }}$ is the effective yield roof drift displacement corresponding to the end point of the elastic portion in the idealized bilinear curve.

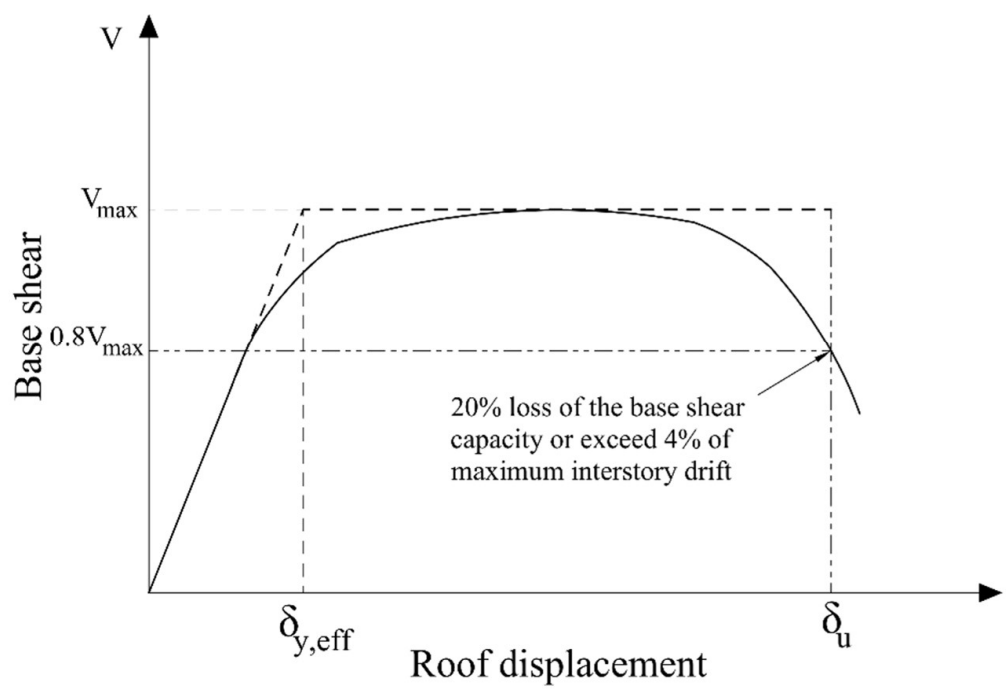

Fig. 6. FEMA P695 [49] idealized nonlinear static pushover curve with additional story collapse criterion based on FEMA356 [50].

\section{Results and discussions}

The nonlinear models of the original and retrofitted frames were analyzed for each input vector generated by LHS. The number of needed samples (N) was calculated using Eq. (2) for all the output variables $\left(V_{\max }, \delta_{u}\right.$, etc.). For better illustration, Fig. (7) shows the number of samples (N) still needed for LHS to converge after $\mathrm{k}_{0}$ samples have been drawn for ultimate roof displacements $\left(\delta_{u}\right)$ of 6-flexural, 6-confined, and 6-combined models. As indicated, the convergence criterion was fulfilled after 660, 622, and 218 samples in the 6-confined, 6combined, and 6-flexural frames, respectively. It is worth noting that these values are the least 
number of required samples while all of the frames were analyzed for 1000 samples generated by LSH to obtain more accurate results.

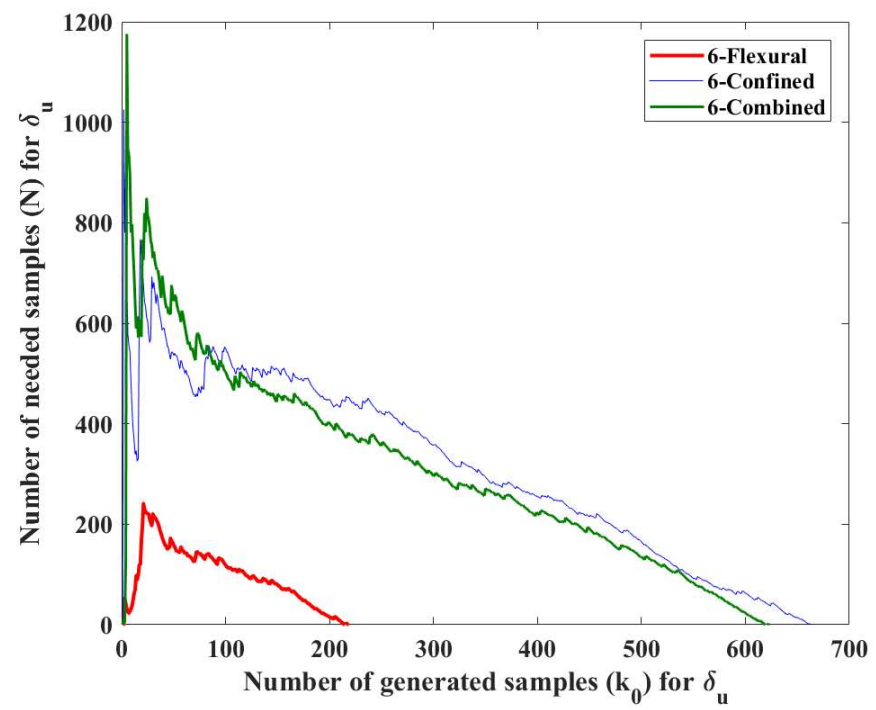

Fig. 7. The number of samples needed for LHS convergence in the ultimate roof displacement $\left(\delta_{u}\right)$ for frames retrofitted with 6 layers of FRP.

The pushover curves of the original and retrofitted frames are plotted in Figs. 8-11. Highlighted points in these figures are also the cap and collapse points. In the cap points, the frames exhibited the maximum base shear capacity, whereas the collapse points were obtained based on the collapse criteria stated in Fig. 6Error! Reference source not found.. Nonetheless, these points were distributed in some models into two different ranges. For example, in the original frame, the collapse points were scattered into two ranges of ultimate roof displacement, $\delta_{u}$ (Fig. 8). In fact, the variation in input parameters changed the collapse mechanism of the frame so that the collapse in 477 samples occurred in the first story. However, in the remaining (i.e., 523) samples, the original frame experienced collapse in the third story. Similar shifts also occurred with substituting the beam-sway collapse mechanism with that of column-sway.

Variation of the random variables can change dynamic parameters such as frequency, modal participation factor, and modal mass coefficient. However, the results of the current study indicated that by considering the same material and mass properties, all the original and retrofitted frames had approximately similar dynamic characteristics as observed in Table 4. This trend was anticipated considering the negligible intervention of FRP laminates in terms of mass and stiffness, particularly for the confinement retrofitting scheme. 


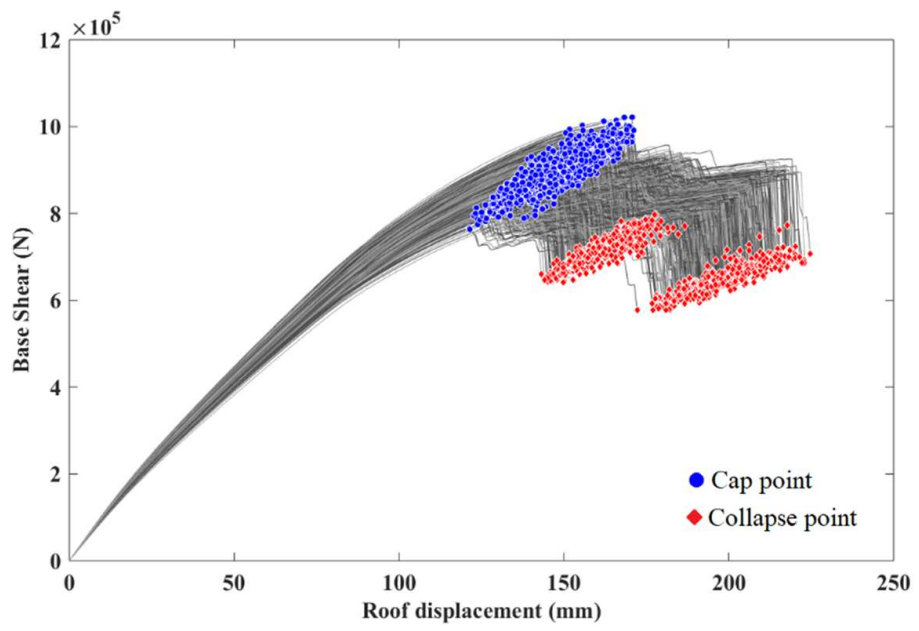

Fig. 8. Pushover curves obtained from 1000 analyses of the original frame. 


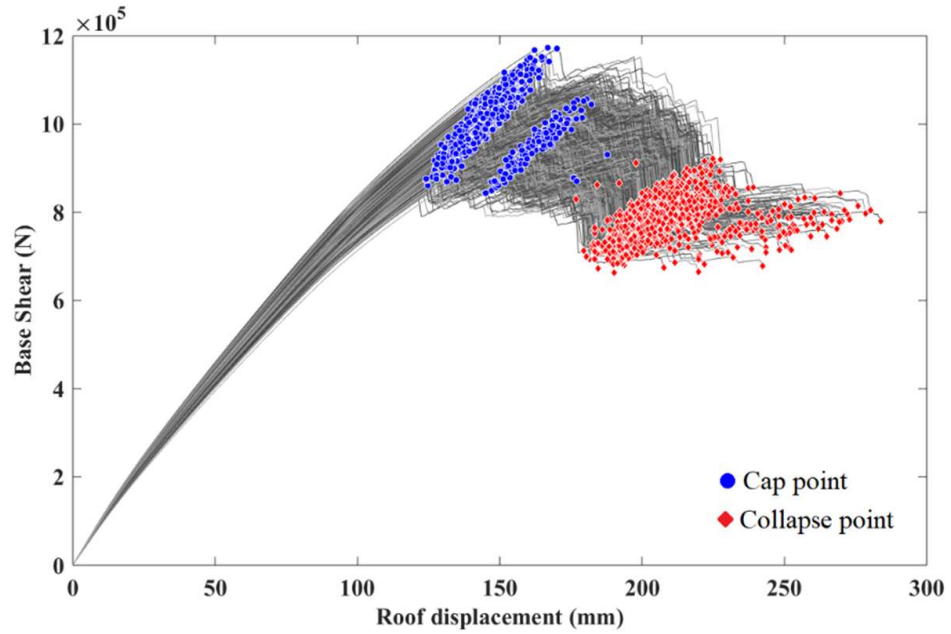

(a)

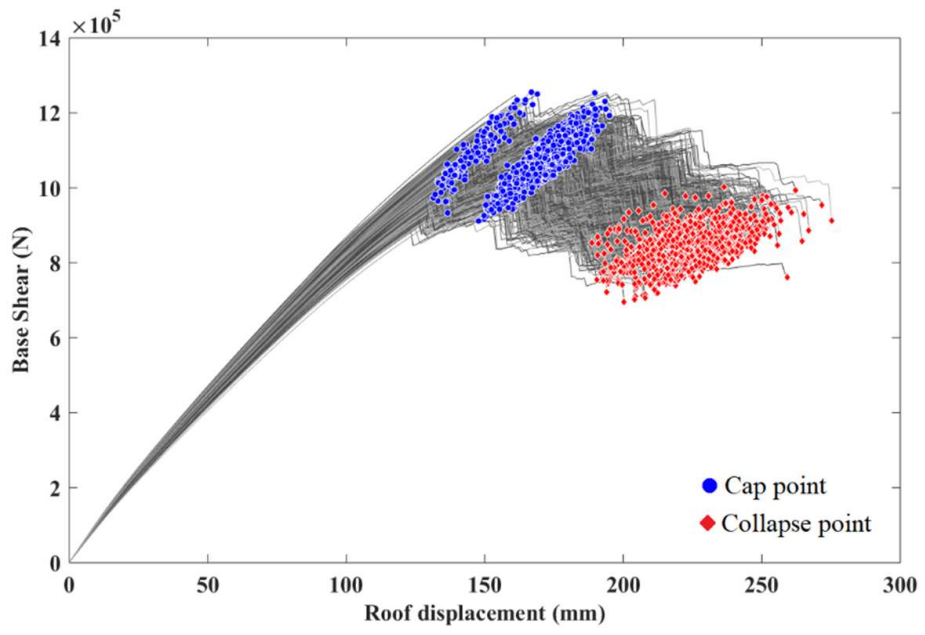

(b)

Fig. 9. Pushover curves obtained from 1000 analyses of (a) 3-Flexural, and (b) 6-Flexural frames. 


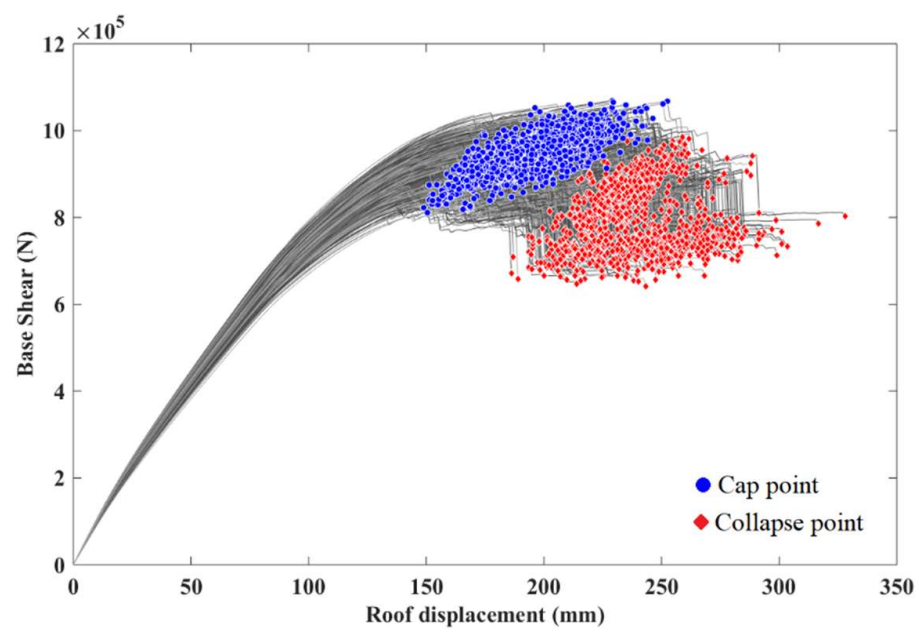

(a)

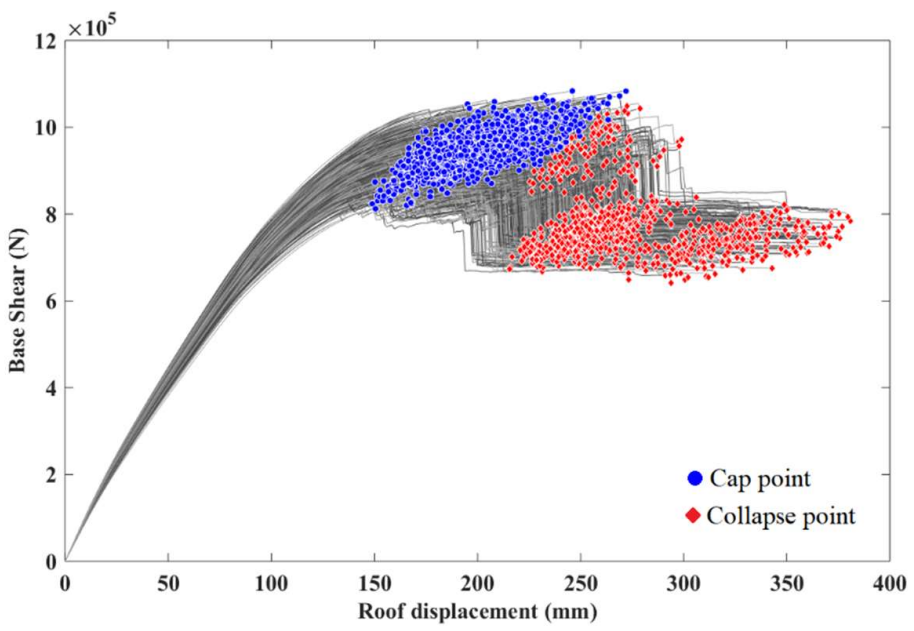

(b)

Fig. 10. Pushover curves obtained from 1000 analyses of (a) 3-Confined, and (b) 6-Confined frames 


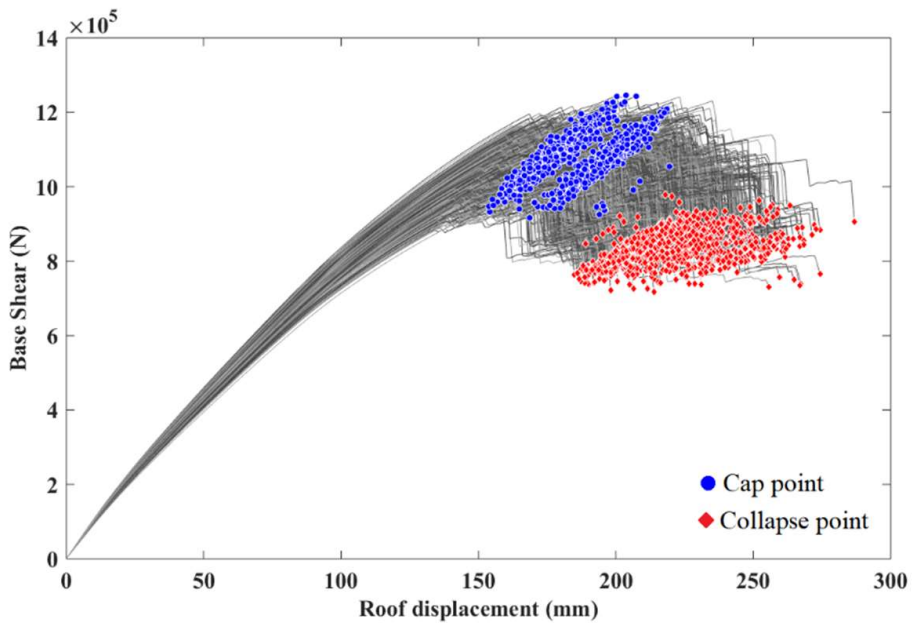

(a)

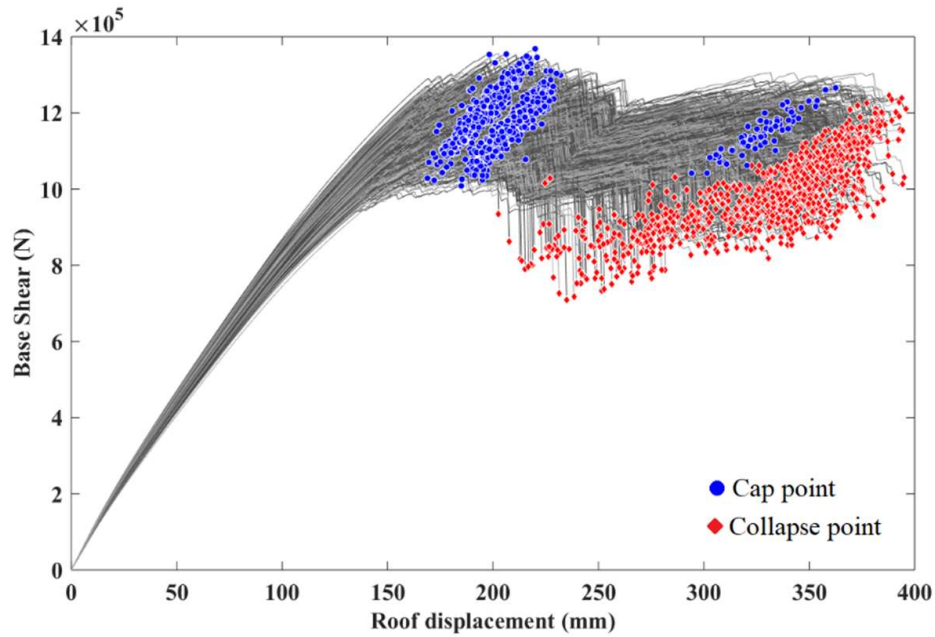

(b)

Fig. 11. Pushover curves obtained from 1000 analyses of (a) 3-Combined, and (b) 6-Combined frames. 
Table 4. Dynamic characteristics the first mode of the analyzed frames

\begin{tabular}{cccc}
\hline Frame & $\begin{array}{c}\text { fundamental period } \\
T_{1}(s)\end{array}$ & $\begin{array}{c}\text { modal mass coefficient } \\
\left(\alpha_{1}\right)\end{array}$ & $\begin{array}{c}\text { modal participation } \\
\text { factor }\left(P F_{1}\right)\end{array}$ \\
\hline Original & 0.781 & 0.771 & 1.309 \\
\hline 3-Flexural & 0.776 & 0.772 & 1.308 \\
\hline 6-Flexural & 0.772 & 0.773 & 1.308 \\
\hline 3-Confined & 0.781 & 0.771 & 1.309 \\
\hline 6-Confined & 0.781 & 0.771 & 1.309 \\
\hline 3-Combined & 0.776 & 0.772 & 1.308 \\
\hline 6-Combined & 0.772 & 0.773 & 1.308 \\
\hline
\end{tabular}

With respect to the probability distribution of the results, Fig. 12 compares the Empirical and Normal Cumulative Distribution Functions (ECDF and NCDF, respectively) of the maximum frame capacity $\left(\mathrm{V}_{\max }\right)$ for the original frame and those retrofitted with 3 layers of CFRP. Clearly, the results very closely followed a normal distribution due to the observance of the convergence criterion (based on a normal distribution) for the number of samples.

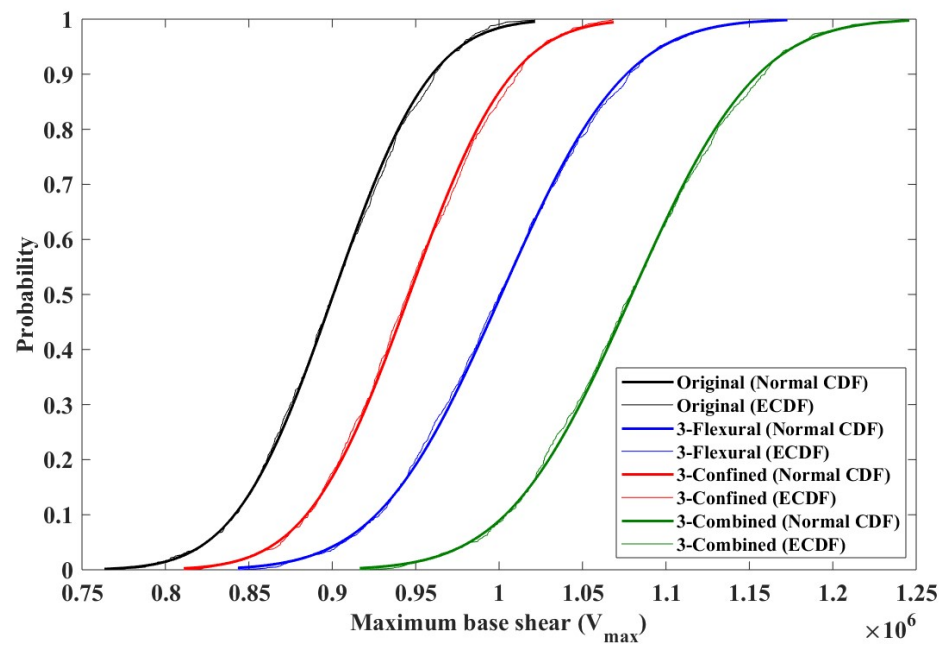

Fig. 12. Empirical Cumulative Distribution Function (ECDF) and Normal Cumulative Distribution Function (NCDF) for maximum frame capacity $\left(\mathrm{V}_{\max }\right)$ in 3-layer retrofitted frames.

For all the pushover curves of the analyzed frames, the idealized bilinear curves were obtained based on FEMA P695 [49]. For the sake of brevity, Fig. 13 presents the average curves for 
each frame, which were calculated by taking into account different sources of uncertainty. They can now be utilized to assess the effectiveness of each retrofitting scheme in terms of capacity and ductility.

\subsection{Capacity evaluation}

According to the average idealized curves shown in Fig 13, all the adopted retrofitting schemes could increase the capacity of the original frame. However, some schemes were more effective than others. For example, using 3 layers of confining FRP wraps in columns (3-Confined) was able to enhance the capacity of the original frame by only $5 \%$ while increasing the number of confining layers (6-Confined) was found inefficient in achieving higher increments. This performance may be justified by considering the capacity of the beams as they were not retrofitted in the confining schemes. In fact, the beams reached their maximum capacity as a result of adding three layers of FRP wraps and the overall lateral strength of the frame was governed by their behavior. As a result, increasing the number of wrapping layers in columns to six was not able to produce any significant changes in this pattern.

In contrast, based on the bilinear curves of Fig. 13, using flange-bonded FRP retrofits was an effective method for capacity enhancement in the original frame. For instance, schemes with 3 and 6 layers of flexural FRP in beams and columns led to higher values of base shear capacity by about $12 \%$ and $20 \%$, respectively. On the other hand, using a combination of flange-bonded and confining FRP retrofits offered the most efficient method for increasing frame capacity. For example, the 3-combined frame showed a $20 \%$ increment in frame capacity, which was equal to that achieved by using 6 layers of flange-bonded FRP solely (6-Flexural). Increasing frame capacity through the application of more confining layers in columns was possible after the beams had been strengthened with flange-bonded FRP composites. These results indicate that the frame with the 6-combined retrofitting scheme showed increased capacity by an average of about $31 \%$ higher than that of the original frame. This enhancement was $50 \%$ higher than that achieved by the 3-Combined scheme. It may, thus, be concluded that when considerable increases are sought in the capacity of the original frame through using more effective wrapping layers in columns, the beams should be strengthened simultaneously. 


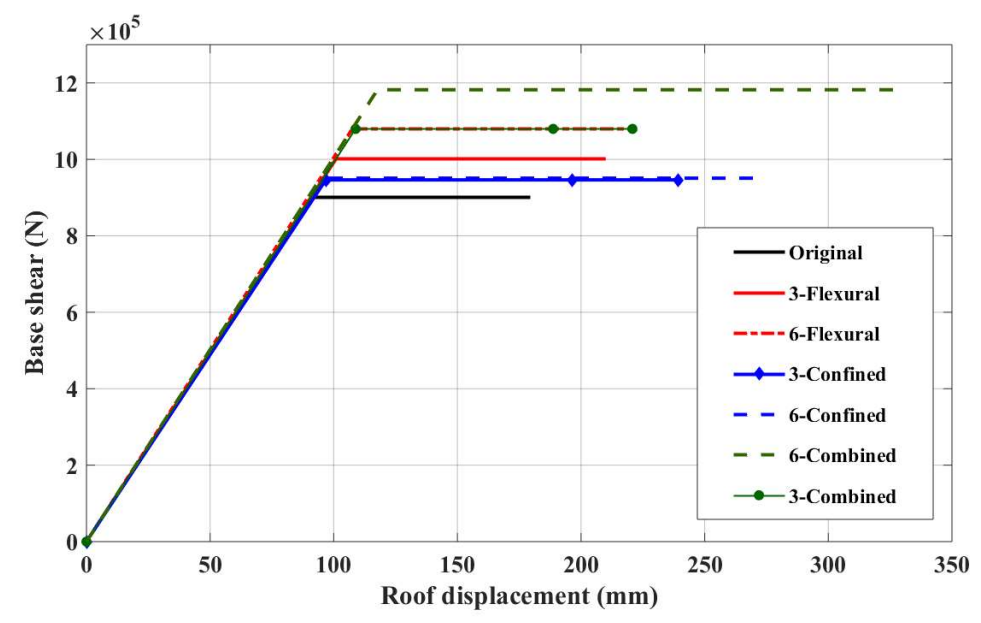

Fig. 13. Average idealized pushover curves for the original and retrofitted frames.

To elucidate the effectiveness of different retrofitting schemes on the capacity of the original frame, fragility curves were obtained for all the studied frames in terms of spectral acceleration capacity $S_{a}(g)$ as defined by[51]:

$$
S_{a}(g)=\frac{V_{\max } / w}{\alpha}
$$

where, $w$ is the effective seismic weight of the frame and $\alpha$ is the modal mass coefficient for the first natural mode of vibration. Fig. 14 compares the fragility curves of the original and retrofitted frames. The Maximum Considered Earthquake (MCE, $2 \% / 50$ years with $\mathrm{S}_{\mathrm{a}}=0.45 \mathrm{~g}$ ), taken equal to 1.5 times the Design Basis Earthquakes (DBE, $10 \% / 50$ years with $\mathrm{S}_{\mathrm{a}}=0.3 \mathrm{~g}$ ), was used to obtain the collapse probability of the studied frames. Evidently, the collapse probability of the original frame is $77 \%$ for the MCE hazard level. However, this probability reduced to around $40 \%$ for the frames retrofitted only with FRP wrapping of the columns (3-Confined and 6-Confined). In addition, using more wrapping layers (6-Confined) without beam strengthening was not effective in decreasing frame collapse probability. It is also apparent from Fig 14 that using 3 flexural layers of FRP wraps reduced the collapse probability of the original frame by about $13 \%$. On the other hand, for the other three solutions (6-Flexural and 3-Combined, and 6-Combined), the collapse probability in the MCE level was found very small, indicating that these schemes were the most reliable for achieving enhanced capacity. 


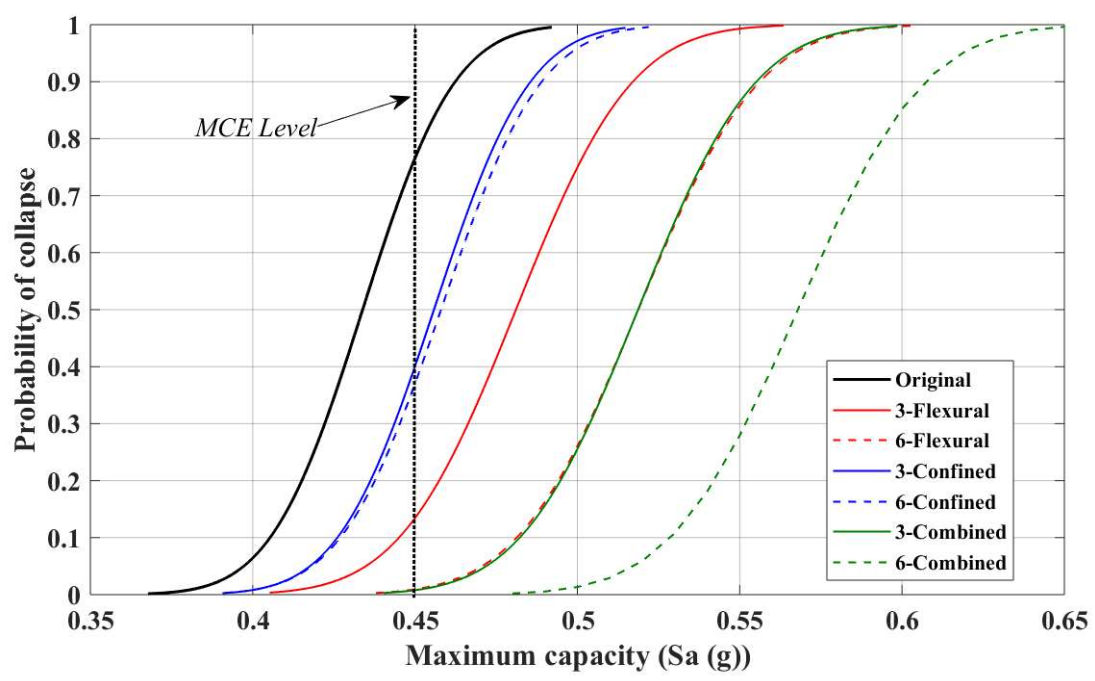

Fig. 14. Fragility curves for the original and retrofitted frames.

\subsection{Ductility evaluation}

For each of the pushover curves obtained, an idealized bilinear curve was derived to determine the ductility factor $\left(\mu_{t}\right)$ based on Eq. (5). Fig. 15 shows the normal probability distribution function of this factor for all the retrofitting schemes. In some cases, the ductility improvement was negligible. For instance, the ductility factor obtained for the frames strengthened with 3 and 6 layers of flange-bonded FRP layers was on average by $7 \%$ higher than that of the original frame. In addition, increasing the number of flange-bonded layers from 3 to 6 in the flexural scheme was solely able to decrease the dispersion (standard deviation) of the ductility value while the average value remained similar. In contrast, using wrapping layers on columns led to considerable enhancements in the values of both frame ductility and dispersion. Compared to the original frame, ductility factors increased by $27 \%$ and $44 \%$ in the 3 -Confined and 6 Confined frames, respectively. Interestingly, the frame with a combination of 3 layers of flexural and confining FRP composites exhibited only a small increment in its ductility (about $4 \%$ on average). Such behavior can be explained using the average pushover curves shown in Fig. 13. Despite the increase in the value of $\delta_{u}$ in the 3-combined frame, $\delta_{y, e f f}$ also became larger as the FRP flexural retrofits were able to postpone the yielding of steel rebars to a higher strength level. As a result, the ratio of these two parameters remained approximately constant. In the 6-Combined frame, the increment gradient for $\delta_{u}$ was greater than that of $\delta_{y, e f f}$, which led to a $43 \%$ higher ductility than that experienced by the original frame. It may be concluded 
that using FRP wraps in columns will be the most effective method when a retrofitting scheme was aimed at increasing only the ductility behavior of a poorly-confined frame. If the target is to achieve enhancements in both the capacity and ductility factor, the solution would then fail to increase ductility in cases where the rates of increment in $\delta_{u}$ and $\delta_{y, \text { eff }}$ are identical.

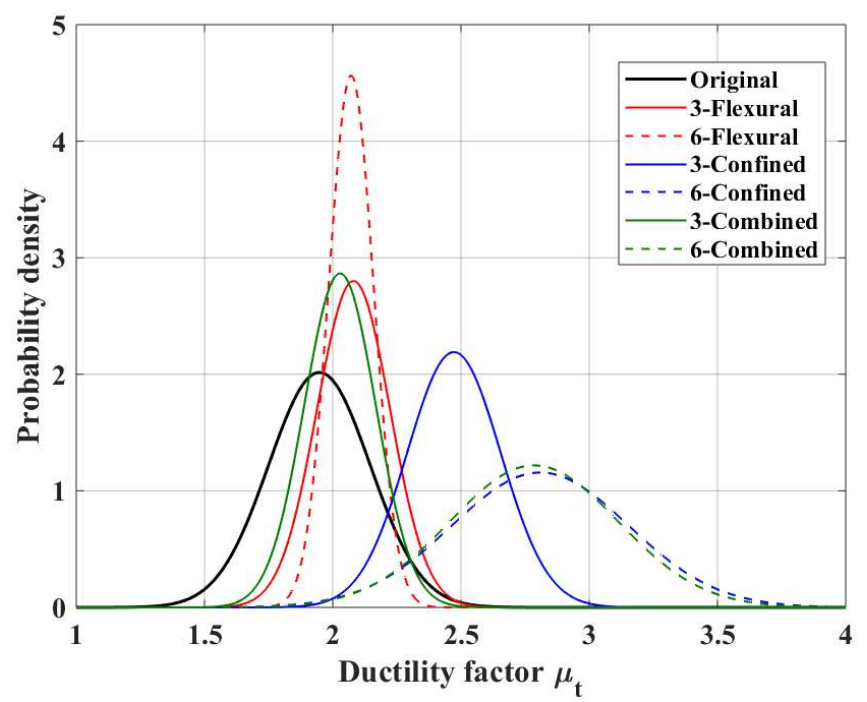

Fig. 15. Normal probability distribution of the ductility factor for different retrofitting schemes.

\section{Failure modes}

Variation in input variables and different retrofitting schemes were found capable of changing the failure mode of the frame. Fig. 16 shows the collapse frequency in different stories of the studied frames. For about half of the samples (i.e. 477 samples), the original frame collapsed in the first story while the collapse of the third story was observed in the remainder. Frames that had only been retrofitted with flange-bonded FRP composites (3-Flexural and 6-Flexural) failed in the first story in all the 1000 samples. A similar pattern was observed in the 3Combined frames where 3 flexural and 3 confining layers were used simultaneously. However, the collapse patterns of the confined frames (3-confined and 6-confined) exhibited greater discrepancies, with failures distributed among the $1^{\text {st }}, 2^{\text {nd }}$, and $3^{\text {rd }}$ stories. In the case of the 6Combined retrofitting scheme, 200 samples caused a collapsed state in the first story while for the remainder, failure of the frame was attributed to the collapse in the second story. These results demonstrate that uncertainties and differences in retrofitting schemes are also involved in the collapse mechanisms of RC frames retrofitted with FRP composites. 


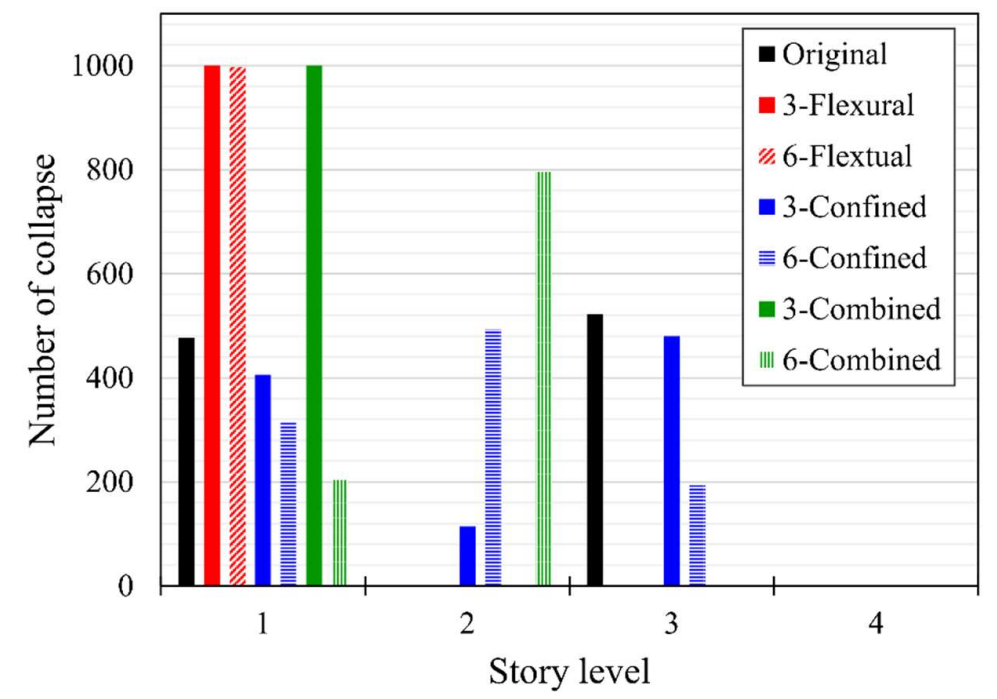

Fig. 16. Collapse frequency in different stories of the original and retrofitting schemes.

\section{Conclusions}

Using a reliability-based approach, this paper examined the collapse capacity and ductility of ordinary RC frames retrofitted with externally bonded FRPs. To this end, wrapping and flangebonded FRPs, as two well-known techniques, were used in different configurations and combinations to retrofit a poorly-confined four-story building. The performance of retrofitting schemes was evaluated using a reliability approach taking into account different sources of uncertainty. Based on the obtained results, the following conclusions can be drawn:

- Improvement in the collapse capacity of frames retrofitted with only 3 layers of FRP layers on the columns (3-Confined frame) was negligible (around 5\%) compared to the original frame. In addition, increasing the confining layers to six (6-Confined frame) was found ineffective as the overall lateral strength of the frame has controlled by the beams.

- Using flange-bonded FRPs was an effective method for capacity enhancement in the original frame. Using 3 and 6 flexural FRP layers in the beams and columns led to higher base shear capacities in the frames by about $12 \%$ and $20 \%$, respectively.

- The frame with a combination of flange-bonded and wrapping layers (3-Combined and 6-Combined) showed about higher capacities by $20 \%$ and $31 \%$, respectively, relative to that of the original frame. Increasing frame capacity through using more confining 
layers in columns is, therefore, possible if the beams are already strengthened with flange-bonded FRP composites.

- Based on the fragility curves obtained for all the retrofitted schemes, the 6-Flexural, 3Combined, and 6-Combined frames were found to provide more reliability for collapse (lower collapse probability) under an MCE earthquake. As a result, they were identified as the most reliable retrofitting schemes for the original frame with respect to capacity.

Regarding ductility, the following conclusions may be drawn from the results:

- Using 3 and 6 flange-bonded FRP layers led to non-significant effects on the ductility factor of the frame. In addition, the average value of the ductility factor remained unchanged when the number of flange-bonded layers was increased from 3 to 6 .

- Compared to the original frame, those retrofitted with 3 and 6 wrapping layers on columns exhibited higher ductility values of around $27 \%$ and $44 \%$, respectively. These improvements confirmed the effectiveness of the wrapping technique in increasing the ductility of the original frame.

- In the 3-Combined frame, equal increments in ultimate roof displacement and yield strength of the frame led to only a small increment in its ductility (about $4 \%$ on average). However, the frame experienced $43 \%$ higher ductility than the original frame when the number of layers was increased to 6 . In consequence, the gradients of the strength and ductility enhancement were identified as factors affecting RC frames retrofitted with externally bonded FRPs.

Finally, the results also demonstrated that variation in structural parameters and the use of different retrofitting schemes have drastic effects on the failure mode of the frame. It should be mentioned at last that the above-mentioned conclusions are restricted to the case-study structure and for the selected parameters. More extensive investigations need to be conducted with different structures and FRP types to gain more reliable and generalizable results.

\section{References}

[1] Eslami A, Ronagh HR. Experimental investigation of an appropriate anchorage system for flangebonded carbon fiber-reinforced polymers in retrofitted RC beam-column joints. Journal of Composites for Construction. 2013;18:04013056.

[2] Eslami A, Dalalbashi A, Ronagh HR. On the effect of plastic hinge relocation in RC buildings using CFRP. Composites Part B: Engineering. 2013;52:350-61.

[3] Garcia R, Hajirasouliha I, Pilakoutas K. Seismic behaviour of deficient RC frames strengthened with CFRP composites. Engineering Structures. 2010;32:3075-85. 
[4] Mostofinejad D, Mahmoudabadi E. Grooving as alternative method of surface preparation to postpone debonding of FRP laminates in concrete beams. Journal of Composites for Construction. 2010;14:804-11.

[5] Eftekhar M, Ya'ghubi M. Using boring to postpone debonding of CFRP-composite concrete beams. Journal of Composites for Construction. 2015;20:04015035.

[6] Eslami A, Shayegh HR, Moghavem A, Ronagh HR. Experimental and analytical investigations of a novel end anchorage for CFRP flexural retrofits. Composites Part B: Engineering. 2019;176:107309. [7] Ronagh HR, Eslami A. Flexural retrofitting of RC buildings using GFRP/CFRP-A comparative study. Composites Part B: Engineering. 2013;46:188-96.

[8] Eslami A, Ronagh HR, Mostofinejad D. Analytical Assessment of CFRP Retrofitted ReinforcedConcrete Buildings Subjected to Near-Fault Ground Motions. Journal of Performance of Constructed Facilities. 2016;30:04016044.

[9] Di Ludovico M, Prota A, Manfredi G, Cosenza E. Seismic strengthening of an under-designed RC structure with FRP. Earthquake engineering \& structural dynamics. 2008;37:141-62.

[10] Balsamo A, Colombo A, Manfredi G, Negro P, Prota A. Seismic behavior of a full-scale RC frame repaired using CFRP laminates. Engineering Structures. 2005;27:769-80.

[11] Valente M, Milani G. Alternative retrofitting strategies to prevent the failure of an under-designed reinforced concrete frame. Engineering Failure Analysis. 2018;89:271-85.

[12] Valente M. Seismic upgrading strategies for non-ductile plan-wise irregular R/C structures. Procedia Engineering. 2013;54:539-53.

[13] Wang N, Ellingwood BR, Zureick A-H. Reliability-based evaluation of flexural members strengthened with externally bonded fiber-reinforced polymer composites. Journal of Structural Engineering. 2010;136:1151-60.

[14] Plevris N, Triantafillou TC, Veneziano D. Reliability of RC members strengthened with CFRP laminates. Journal of Structural Engineering. 1995;121:1037-44.

[15] Wieghaus KT, Atadero RA. Effect of existing structure and FRP uncertainties on the reliability of FRP-based repair. Journal of Composites for Construction. 2010;15:635-43.

[16] Huang X, Sui L, Xing F, Zhou Y, Wu Y. Reliability assessment for flexural FRP-Strengthened reinforced concrete beams based on Importance Sampling. Composites Part B: Engineering. 2019;156:378-98.

[17] Zou Y, Hong HP. Reliability assessment of FRP-confined concrete columns designed for buildings. Structure and Infrastructure Engineering. 2011;7:243-58.

[18] Ali O. Structural reliability of biaxial loaded Short/Slender-Square FRP-confined RC columns. Construction and Building Materials. 2017;151:370-82.

[19] Baji H, Ronagh HR, Li C-Q. Probabilistic assessment of FRP-confined reinforced concrete columns. Composite Structures. 2016;153:851-65.

[20] Zou X, Wang Q, Wu J. Reliability-based performance design optimization for seismic retrofit of reinforced concrete buildings with fiber-reinforced polymer composites. Advances in Structural Engineering. 2018;21:838-51.

[21] Ali O, Bigaud D, Riahi H. Seismic performance of reinforced concrete frame structures strengthened with FRP laminates using a reliability-based advanced approach. Composites Part B: Engineering. 2018;139:238-48.

[22] El-Reedy MA. Reinforced Concrete Structural Reliability: Taylor \& Francis Group; 2013.

[23] American Concrete Institute Committee 117. Specifications for Tolerances for Concrete Construction and Materials and Commentary (ACI 117-06). American Concrete Institute; 2006.

[24] Vamvatsikos D, Cornell CA. Incremental dynamic analysis. Earthquake Engineering \& Structural Dynamics. 2002;31:491-514.

[25] Deylami A, Mahdavipour M. Probabilistic seismic demand assessment of residual drift for Buckling-Restrained Braced Frames as a dual system. Structural Safety. 2016;58:31-9.

[26] Jehel P. A look into uncertainty in structural seismic performance arising from additional Rayleigh damping in inelastic time history analysis. International Conference on Structural Safety \& Reliability (ICOSSAR 2013): CRC Press; Taylor and Francis; 2013.

[27] Diniz SM, Frangopol DM. Safety evaluation of slender high-strength concrete columns under sustained loads. Computers \& structures. 2003;81:1475-86. 
[28] Ali O, Bigaud D, Ferrier E. Comparative durability analysis of CFRP-strengthened RC highway bridges. Construction and building materials. 2012;30:629-42.

[29] Kim JH, Lee HS. Reliability assessment of reinforced concrete rectangular columns subjected to biaxial bending using the load contour method. Engineering Structures. 2017;150:636-45.

[30] Atadero RA, Karbhari VM. Calibration of resistance factors for reliability based design of externally-bonded FRP composites. Composites Part B: Engineering. 2008;39:665-79.

[31] Ribeiro S, Diniz S. Reliability-based design recommendations for FRP-reinforced concrete beams. Engineering Structures. 2013;52:273-83.

[32] Diwekar U, David A. BONUS algorithm for large scale stochastic nonlinear programming problems: Springer; 2015.

[33] Nyberg SO. The Bayesian way: introductory statistics for economists and engineers: John Wiley \& Sons; 2018.

[34] American Concrete Institute Committee 318. Building Code Requirements for Structural Concrete (ACI 318-14): American Concrete Institute. ACI; 2014.

[35] Building and Housing Research Center. Iranian Code of Practice for Seismic Resistant Design of Buildings, Standard No. 2800 3th Edition. Tehran2005.

[36] International conference of building officials. Uniform building code (UBC). 1997.

[37] American Concrete Institute Committee 440. Guide for the design and construction of externally bonded frp systems for strengthening concrete structures (ACI 440.2R-17). American Concrete Institute; 2017.

[38] Mazzoni S, McKenna F, Scott MH, Fenves GL. OpenSees command language manual. Pacific Earthquake Engineering Research (PEER) Center. 2006;264.

[39] Mostofinejad D, Akhlaghi A, Eslami A. Estimating the Seismic Performance of CFRP-Retrofitted RC Beam-Column Connections Using Fiber-Section Analysis. Journal of Earthquake Engineering. 2018;22:1092-110.

[40] Lam L, Teng J. Design-oriented stress-strain model for FRP-confined concrete. Construction and building materials. 2003;17:471-89.

[41] Lam L, Teng J. Design-oriented stress-strain model for FRP-confined concrete in rectangular columns. Journal of reinforced plastics and composites. 2003;22:1149-86.

[42] Rocca S, Galati N, Nanni A. Interaction diagram methodology for design of FRP-confined reinforced concrete columns. Construction and Building Materials. 2009;23:1508-20.

[43] Eslami A, Ronagh HR. Effect of FRP wrapping in seismic performance of RC buildings with and without special detailing-A case study. Composites Part B: Engineering. 2013;45:1265-74.

[44] Baji H, Eslami A, Ronagh HR. Development of a nonlinear FE modelling approach for FRPstrengthened RC beam-column connections. Structures: Elsevier; 2015. p. 272-81.

[45] Eslami A, Ronagh HR. Numerical investigation on the seismic retrofitting of RC beam-column connections using flange-bonded CFRP composites. Journal of Composites for Construction. 2015;20:04015032.

[46] Park R, Paulay T. Reinforced concrete structures: John Wiley \& Sons; 1975.

[47] Filippou FC, Bertero VV, Popov EP. Effects of bond deterioration on hysteretic behavior of reinforced concrete joints. 1983.

[48] Guo T, Song L, Zhang G. Numerical simulation of the seismic behavior of self-centering steel beam-column connections with bottom flange friction devices. Earthquake Engineering and Engineering Vibration. 2011;10:229.

[49] Federal Emergency Management Agency (FEMA). Quantification of building seismic performance factors (FEMA P695). Washington, D.C.: FEMA; 2009.

[50] Federal Emergency Management Agency (FEMA). Prestandard and commentary for the seismic rehabilitation of buildings (FEMA356). Washington, D.C.: FEMA; 2000.

[51] Applied Technology Council. Seismic evaluation and retrofit of concrete buildings. California1996. 